\section{QIJEI}

\author{
International \\ Journal for \\ Educational \\ Integrity
}

\title{
Staff and student perspectives on the potential of honour codes in the UK
}

\author{
Nadya Yakovchuk \\ Thinking Writing, Language and Learning Unit, Queen Mary University of London \\ n.yakovchuk@hotmail.co.uk \\ Jo Badge \\ School of Biological Sciences, University of Leicester \\ jlb34@leicester.ac.uk \\ Jon Scott \\ School of Biological Sciences, University of Leicester \\ js50@leicester.ac.uk
}

Keywords: academic integrity, plagiarism prevention, honour code, honor code, focus group

\begin{abstract}
Honour code systems have been long-established in some American universities, associated with cultures of academic integrity. This study considers the perceptions of students and staff, elicited through focus groups and electronic voting, in one UK higher education institution regarding the potential for implementation of these systems in the UK. Whilst the main principles of honour codes were broadly welcomed, implementation in the UK higher education context was perceived as problematic. Although both staff and students saw educational benefits in increased student involvement in the promotion of academic integrity and good academic practice, there was a tension between staff who would like to increase the responsibilities of students and the reality of the students' seeming lack of confidence in their ability to discharge those responsibilities. The introduction of students as participants in plagiarism hearing panels and processes was tentatively supported, potentially offering a route to break down the staff-student dichotomy.
\end{abstract}

\section{Background}

Although academic dishonesty is not a recent phenomenon, it is becoming a focus of deepening concern, particularly in terms of the perceptions of increasingly widespread incidences of plagiarism among university student populations (Franklyn-Stokes \& Newstead, 1995; Larkham \& Manns, 2002; Park, 2003; Brimble \& Stevenson-Clarke, 2005; Duggan, 2006; Selwyn, 2008; Trost, 2009). Concerns exist that this reflects both a blurring, in the digital age with the wealth of freely available material on the web, of the concepts of authorship (Gabriel, 2010), intertextuality (Howard, 2007) and changes in the value systems held by students, with a perceived danger that cheating may become normative behaviour (Brimble \& Stevenson-Clarke, 2005).

There has been an increasingly strongly argued case that plagiarism is actually a complex issue and that institutions should move away from a position where their role is largely to deter, detect and punish academic dishonesty, to one where there is an holistic approach with responsibility being apportioned to students, staff and the institution as a whole (Park, 2004; MacDonald \& Carroll, 2006; JISC, 2011). These

The International Journal for Educational Integrity is available online at: http://www.ojs.unisa.edu.au/journals/index.php/IJEl/

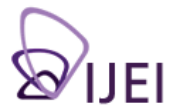


approaches are important not least because plagiarism encompasses a broad spectrum ranging from the deliberate intent to cheat at one extreme to the inadvertent, resulting from poor academic practice, at the other; the latter aspect being exacerbated because students' understanding and the messages given by staff may both be poorly defined (McCabe, 2004; Carroll, 2004; Flint, Clegg, \& Macdonald, 2006). McGowan (2005) proposed addressing this issue through the concept of 'educational integrity' and advocated the provision of an apprenticeship into academic writing so that the penal system could be focused more clearly on those who are the real offenders.

In the US context, a long-standing approach embodying academic integrity within an holistic framework is the honour code system that has been adopted by over 360 universities (Center for Academic Integrity, 2010). With a strong focus on the values that underpin academic work, this system rests on the premise that if ingrained in the institutional culture, these values and associated practices serve as an internal moral guide to empower students to take responsibility for upholding academic standards. This perspective, with its emphasis on the promotion of good scholarly practice, provides a strong counterbalance to the commonly used negative rhetoric of 'academic dishonesty' and 'academic cheating'. In its own literature, the Center for Academic Integrity emphasises the positive nature of its approach to academic integrity through its definition that it is "a commitment, even in the face of adversity, to five fundamental values: honesty, trust, fairness, respect and responsibility" (Center for Academic Integrity, 1999).

The honour codes vary between institutions but can be grouped into two main categories: traditional and modified. Traditional codes place almost all the responsibility for maintaining academic standards on students who usually take a pledge that has a strong moral element to it (McCabe \& Treviño, 2002). In return for the commitment to uphold the principles of academic integrity, students are given privileges and responsibilities, which often include unsupervised exams, exclusive or majority student disciplinary panels and, in some cases, a non-toleration clause - an obligation to report incidents of academic cheating among students (McCabe \& Treviño, 2002). Modified honour codes have been developed more recently in institutions where the campus culture has been less supportive of the traditional code (McCabe \& Pavela, 2000, 2005), but nonetheless, they share two fundamental elements. The first is the ethos that academic integrity is an institutional priority, and the second is the engagement of students in the promotion of academic integrity (McCabe \& Treviño, 2002).

Large-scale studies into the levels of academic dishonesty in institutions that operate honour codes in the US indicate reduced incidence in comparison with non-code institutions (McCabe \& Treviño, 1993; McCabe, 2000; McCabe \& Pavela 2000; McCabe, Treviño, \& Butterfield, 2002). It has been reported that students from code and non-code institutions conceptualise academic integrity differently: the former view honour codes as "an integral part of a culture of integrity that permeates their institutions" (McCabe, Treviño, \& Butterfield, 1999, p. 230). Such strong institutional culture that attaches major importance to academic integrity and actively encourages student involvement in the promotion of core academic values is believed to contribute to students' moral development both within and beyond university years (McCabe \& Treviño, 2002). However, in a longitudinal study of a single institution, spanning the introduction of a modified honour code, Vandehey, Diekhoff and LeBeff (2007) concluded that the honour code did not affect cheating behaviour, reflecting different levels of endorsement of the code between 'cheaters' and 'non-cheaters'. Furthermore, by contrast with McCabe and Treviño's findings that the perception of peer behaviour was the most notable contextual factor influencing levels of academic cheating (McCabe \& Treviño 1993, 1997; McCabe et al. 2002), Vandehey et al. (2007) reported that the deterrent effect of the disciplinary policies was rated higher than peer disapproval in their study. In this case, however, it might be argued that since the honour code was only introduced two years before the final survey of student behaviours, it represents a very different culture to those described by McCabe and coworkers which have been long-established. 
Notwithstanding some of the conflicting evidence, the honour code system appears to offer a potentially viable alternative to more traditional top-down approaches to promoting and ensuring good academic practice among students and, therefore, it is important to explore staff and student perspectives on the potential use of honour codes in the UK. Academic research in this area has been limited. Clarke and Aiello's (2007) exploratory study looking at student perceptions of learning contracts and honour codes is one of the few exceptions. Although their participants appreciated the idea of a positive value-based approach to their academic practice, the students felt that honour codes might not be easily transferred to the UK setting because their tone and style are 'too American'. On a practical level, a recent initiative at Northumbria University has been to draft a non-binding 'academic values agreement', to be distributed among new students, in the form of statements describing the university's and the students' commitments to each other (Shepherd, 2007). Due to the scarcity of both researchgrounded and practice-based output in this area in the UK, further contributions are necessary. The primary aim of the study was to further explore, in the context of one UK university, the attitudes of students and academic staff to the concepts of academic integrity and the honour code system, and to elicit their views regarding the feasibility of incorporating honour codes in the UK higher education context.

\section{Method}

The investigation was undertaken by means of a series of focus groups with staff and students of a UK university. Ethical approval for the project was obtained through the University's research ethics committees.

Participants were recruited by general invitation via a list of course student representatives and a list of staff known to have been involved in plagiarism cases. Overall, 18 staff and 10 students participated in the focus groups (one first-year, five second-year and four final-year students). Participants were drawn from the three main faculty areas of the University. Focus groups were carried out for staff and students separately, following exactly the same procedure. The sessions were audio recorded digitally and later transcribed. Although the initial intention was to explore the potential variation in views between different subject disciplines (and all the focus groups were therefore conducted separately for participants from the A, B and C groups), the limited size of the overall sample does not allow meaningful interdisciplinary comparisons. Quotations from participants are coded using letters A - Faculty of Arts, B - Faculty of Sciences and Faculty of Medicine and Biological Sciences, and C - Faculty of Social Sciences and Faculty of Law.

The overall ethos and the elements of the American honour code system were presented to each focus group. To avoid any preconceived ideas, the specific terms 'honour code' or 'honour code system' were not used, but were referred to obliquely as an 'alternative system' in contrast with the existing UK systems. An electronic voting system (Turning Point) was used to ascertain participants' views on the 12 specific statements relating to the 'alternative system'. The voting process was anonymous but the participants could see the aggregated results immediately after voting.

The 12 statements, grouped into three themes, are presented below.

\section{Community and behaviour}

a. Framing the issue of plagiarism in more positive, rather than negative, terms.

b. Promoting shared values and principles of the academic community as a means of plagiarism prevention.

c. Placing a strong campus focus on academic integrity.

d. Encouraging all parties (students, staff, and administration) to be responsible for maintaining academic integrity. 


\section{Operational issues}

a. Having a code of academic conduct.

b. Having an honour pledge that students are required to sign.

c. Having a non-toleration clause.

d. Having unsupervised exams.

\section{Student involvement}

a. Student involvement in producing / re-writing the code of academic conduct.

b. Student involvement in peer education and instruction.

c. Exclusive student judiciary (panel comprised exclusively of students to consider plagiarism).

d. Partial student judiciary (partial student involvement in a panel to consider plagiarism).

The questions for each of these statements were asked twice, the first time preceded by the following phrase: "In the ideal world: To what extent do you agree with the following?", and the second time by "In the real world: Do you think that the following would work in a UK university?". In this way the participants could indicate to what extent they agreed with a particular idea in principle and then whether they thought it could work in practice in the UK context as a means of reducing plagiarism. Participants were asked to vote to register their responses using a 5-point Likert scale (where $1=$ strongly disagree, 2 = disagree, 3 = neither agree nor disagree, $4=$ agree, $5=$ strongly agree). Free discussion was actively encouraged on each of the statements prior to the voting taking place.

\section{Results and discussion}

All 10 students answered all of the questions posed; however, some staff did not answer every question so their responses range from $n=18$ to $n=14$ (some were temporarily absent from the discussions). Since the sampling procedure tended to favour self-selection and the overall samples were quite small, the findings presented in this paper should be interpreted with caution, however we believe that the results provide a useful indication of views on the issue of honour codes, and it is hoped that this study will stimulate further investigation and debate. 


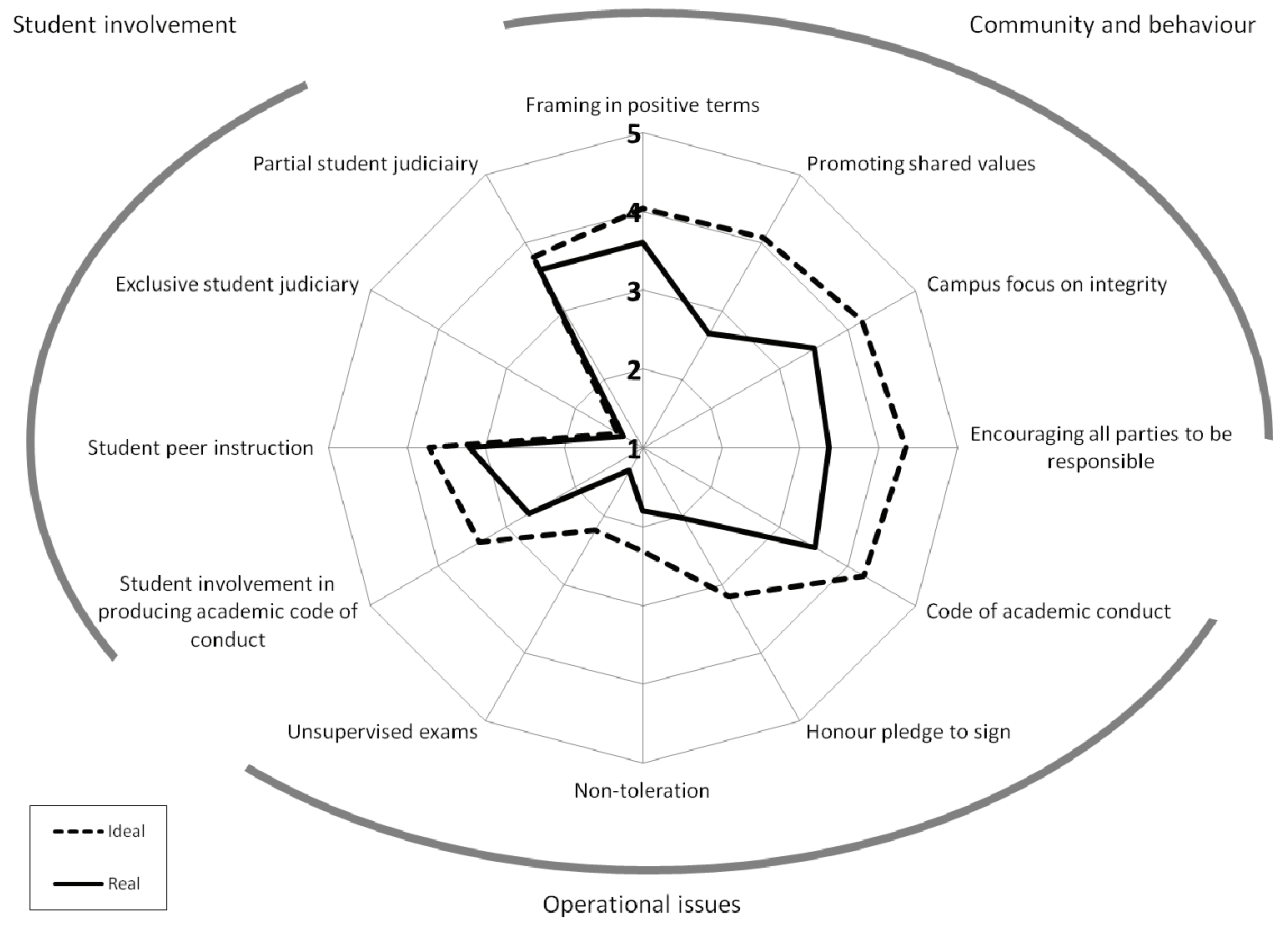

Figure 1: Radar diagram showing the combined responses of staff and students to the statements comparing the ideal and real scenarios. Aggregated scores were used ranging from 5 (strongly agree) to 1 (strongly disagree).

Participants responded more positively to all the questions relating to the 'alternative' (aka honour code) system framed in the context of the 'ideal world' compared with consideration of the 'real world' context of the UK higher education environment (Figure 1). When the participants were separated out the staff were almost invariably more positive in their views than the students.

\section{Community and behaviour}

The respondents viewed the aspects related to community and behaviour in a relatively positive light in the ideal world context, compared to other aspects considered. All, however, were viewed markedly more sceptically when placed in the context of real world implementation.

Consideration of framing the issues in more positive terms as a means of helping prevent plagiarism revealed a difference in the perspective of staff and students. Of the staff, 15 of the 17 agreed with the concept in the ideal world and 14 still felt it was potentially useful in the real world. By contrast, only 6 of the 10 students considered that this approach was theoretically useful, falling to 5 for the real world context. Some of these views are reflected in the following comments:

Sometimes it's very easy to speak about plagiarism all in terms of misconduct, and I can see that there is some advantage in trying to push the argument that what this is designed to do is to help improve study skills, how we present work... (StaffA5)

I know it's a good way to see the whole of plagiarism....and respecting people in a positive light, but it's... if people aren't going to be worried about not being punished, then there's not gonna be any motivation for them... (StudB8) 
The last comment, however, was followed by a compromise view that could bridge the divide for the students, albeit reflecting the positive aspect as a minor component:

I think the idea of academic integrity, sort of getting that across, as well as the University's regulations on plagiarism, I don't think one could take the place of the other, but I think that as a little thing to go on top with it, like to introduce a positive, but reinforce by the negative if you see what I mean. (StudB8)

The responses to the question regarding the 'promotion of shared values and principles of the academic community as a means of plagiarism prevention' showed the largest difference between the ideal and real situations for both staff and students (Figures 1 and 2).

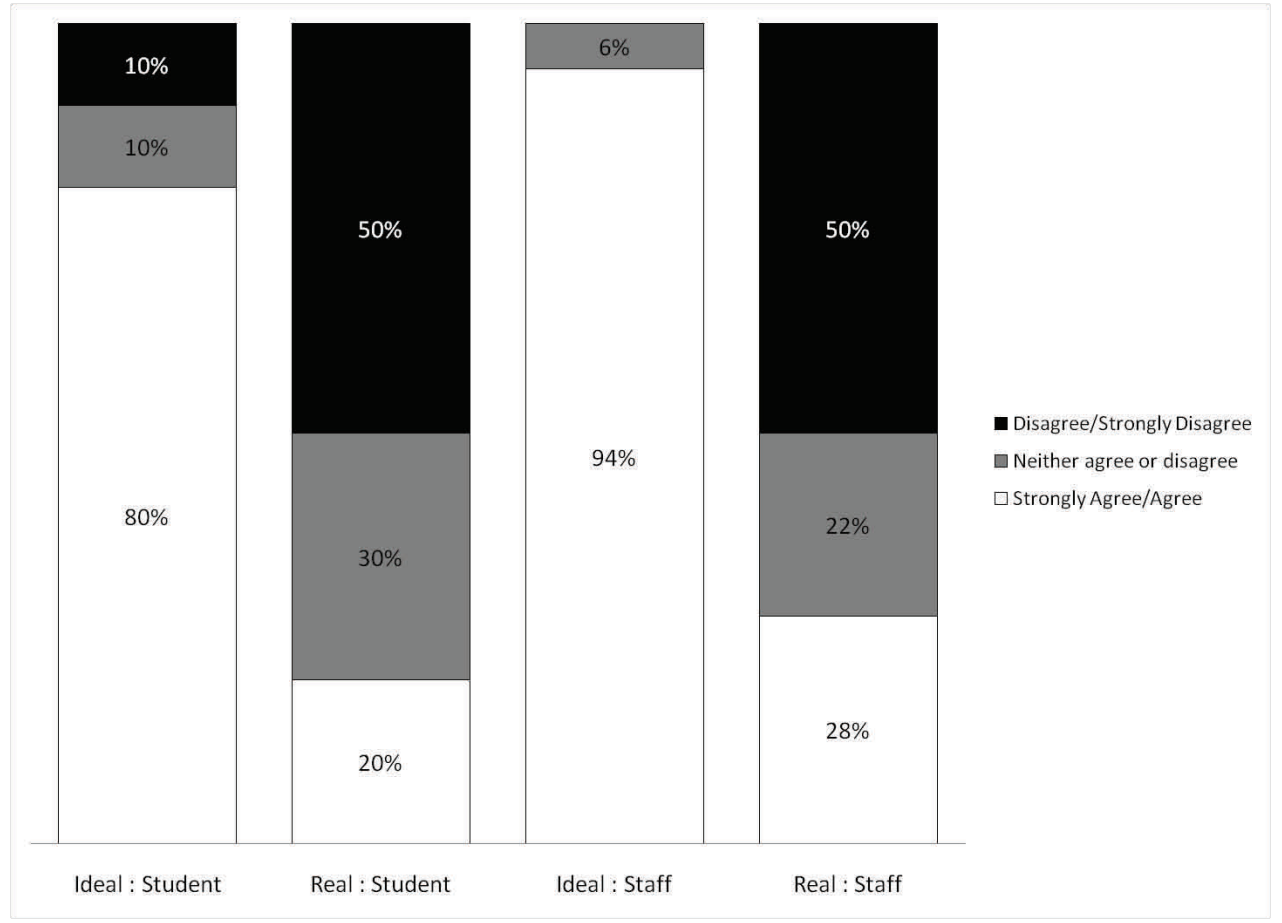

Figure 2: Responses of staff and students to ideal and real scenarios for the statement 'Promoting shared values and principles of the academic community as a means of plagiarism prevention' (students $n=10$; staff $n=18$ ).

Eighty percent of the students (8/10) and $94 \%$ of staff $(17 / 18)$ welcomed the idea of the promotion of shared values of academic integrity, but this dropped to $20 \%$ and $28 \%$ respectively, as to whether this would help in preventing plagiarism in reality. The following comment is quite telling in this respect:

I think it is kind of hard to vote on it, because there're kind of two bits to it. I have no issue with promoting those, I'm very happy to promote them, but if you're asking whether we think they would work in terms of actually preventing plagiarism, I don't think they would work. I think we should still promote them, but I don't think it would work. (StaffA3)

There was acknowledgement of the dependence of the behaviour of a community on its constituents and possible discrepancies between different value systems, as well as of the transient, and often instrumental, nature of most students' presence in the academic community: 
Well, you talk about an academic community of shared values, you're assuming that everybody has the same values, and they don't. We have a very open and very diverse academic community... (StaffC5)

This idea of community is very... top-down if you like. Very few students I think are committed to being academics or being a member of their academic communities, especially since the universities have become so commercialised. They're buying something, and if you can get a free gift or if you can pick something up for free on the way out, then that's nothing to do with shared values at all I think, it's getting a product. And especially within the internationalised student body, heavily internationalised ... who are here for a very short period, and the academic community means very little I would have thought. (StaffC6)

Overall, the theme of commercialisation of higher education came through quite strongly in all staff focus groups, whereas students did not seem to raise this issue.

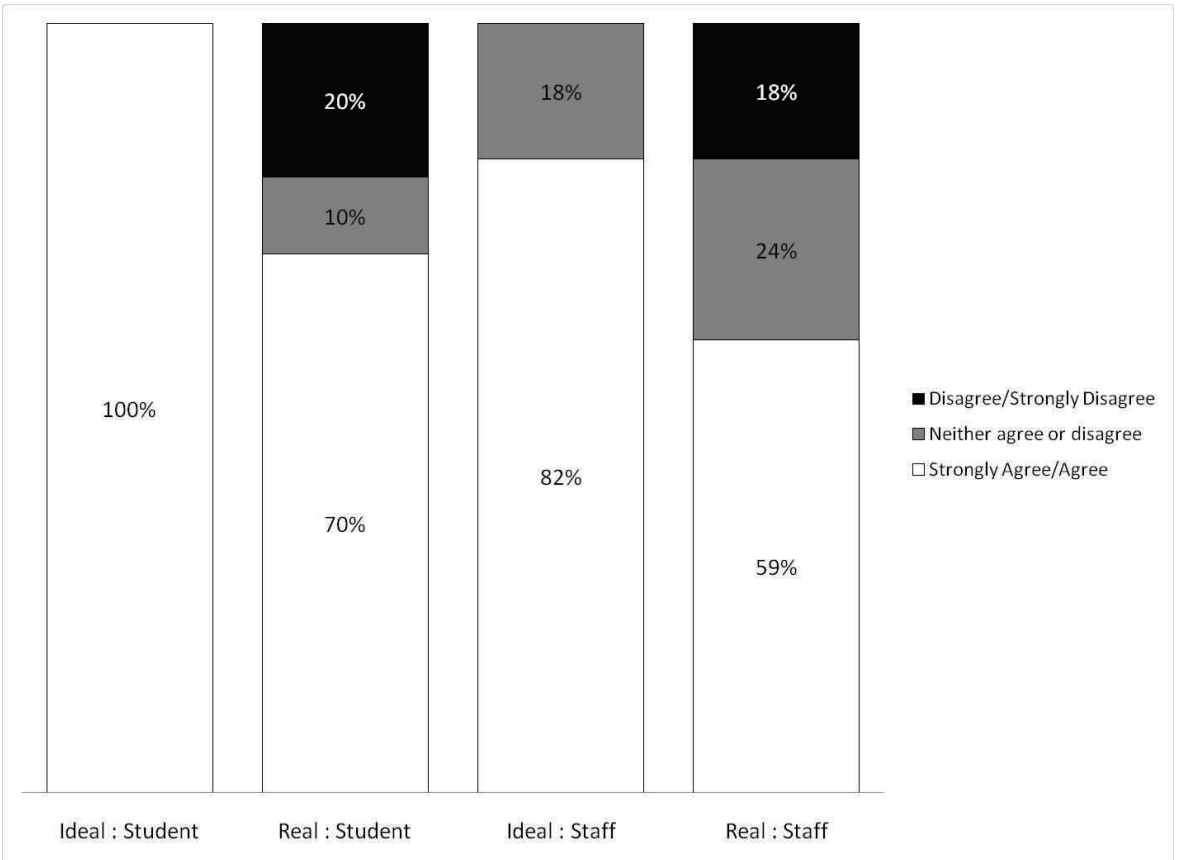

Figure 3: Responses of staff and students to ideal and real scenarios for the statement 'Placing a strong campus focus on academic integrity' (students $n=10$; staff $\mathrm{n}=17$ ).

Placing a campus-wide focus on academic integrity was viewed positively by both students and staff in the ideal world (100\% and $82 \%$, respectively) (Figure 3 ) and the majority of participants still agreed with this approach in the real world scenario $(70 \%$ and $59 \%$ ). However, it was noted that this approach may prove difficult in a distancelearning context, which would pertain to a significant proportion of students:

I think in a distance learning context, some of this is quite difficult. ...I think we can do something, but obviously a strong campus thing, you have to try and create that at a distance which is very hard to do if not impossible. (StaffC4)

Creating an effective community and development of a campus focus on academic integrity largely depend on whether all members of that community are prepared to take responsibility for its successful functioning. 
The idea of encouraging all parties to be responsible for maintaining academic integrity was agreed with by approximately $90 \%$ of both staff and students in the ideal scenario (Figure 4); however, in terms of it making a realistic difference to plagiarism prevention in the UK context the participants were more sceptical, particularly the staff of whom only about half agreed with this view.

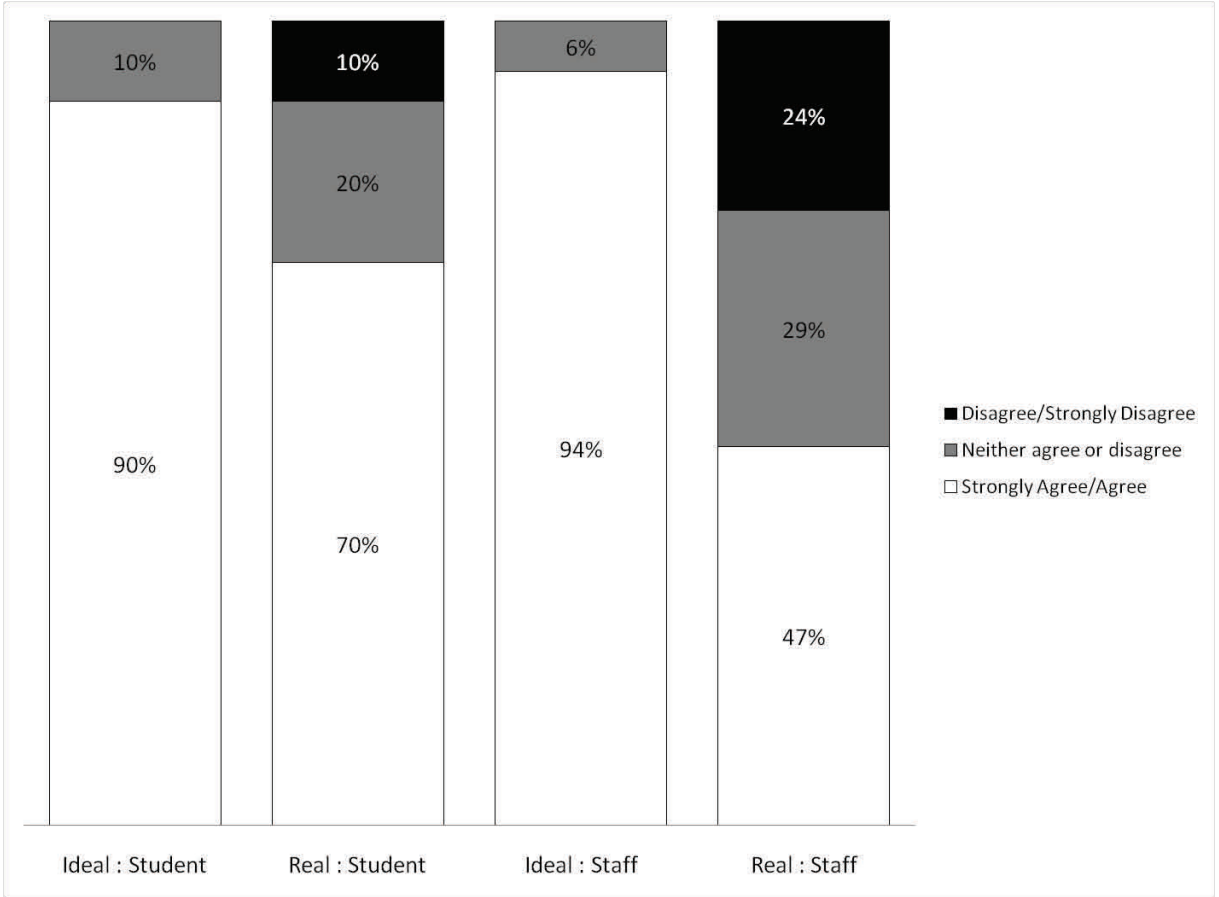

Figure 4: Responses of staff and students to ideal and real scenarios for the statement 'Encouraging all parties (students, staff, administration) to be responsible for maintaining Academic Integrity' (students $n=10$; staff $n=17$ ).

The following comment illustrates one of the possible concerns:

The other thing that I was thinking about here, which is exactly what the word 'responsibility' refers to here. We still have to have a system for identifying plagiarism, and who is going to do that? And it didn't seem obvious to me that students would necessarily, I'm not sure I trust the students enough to identify plagiarism (laughter). (StaffB5)

This comment implies the issue of staff-student separation, which can be quite contradictory to the whole idea of a community and equal treatment of its members. We prompted participants further to voice their views on the idea of moving away from staff-student dichotomy towards a more equal relationship. The views expressed seemed to be quite wide-ranging. Some students felt that it was already the case and that it was a good idea:

And when they [staff] respect you I think it makes learning a bit more fun as well. If they're gonna force it down your throat, after a little while everybody is gonna start rebelling... (StudB9)

'Cause they become more personal with you and you want to learn from them, because they're basically your friend, and they're sharing their knowledge with you, they're not talking at you anymore, they're talking with you. (StudB6) 
Some student participants emphasised the difference between school and university in this respect:

You move into university and you're an adult, and you should be treated as an adult, and in my eyes you're on the same level as them, adults (Stud B7);

while others pointed to a transition towards a community throughout the university years:

We do see this, by the time you're definitely a third-year ... they treat you as an equal, as a peer, rather than them being someone in authority. So definitely, but it's instilled in us from the first year that as you build up through uni you're more of a community, not as a hierarchy anymore. (StudB8)

In staff discussions, some departments seemed to come out as having less 'us and them' dichotomy than others. For example, a geology lecturer noted that as a result of doing field trips, staff and students at that department tend to know each other well and work in a community where there is collective responsibility (StaffB1). In medicine, staff and students work closely 'both academically and in a clinical workplace'; however, in spite of such a 'close-knit relationship', there is 'a demarcation line when there's a need to' (StaffB3).

This idea of a 'demarcation line' between staff and students featured in most discussions, and its inevitability, and hence certain scepticism over the possibility of having a community approach in reality, is exemplified in the following exchange:

There's always going to be a relationship between staff and students that necessarily has to be unequal, isn't there? You can talk about a community approach which to me gives some kind of sense of shared values and shared ownership over things, but it's always going to be the University that carries out the administration or does the marking [...]. I get the sense that this kind of approach couldn't necessarily be very real, you know, it'll always perhaps be a kind of a feeling, or touchy feely... (StaffA6)

One of the recurring concerns that was raised by staff reflected the on-going changes in the nature of university education, in particular the increased diversity of the student population, the internationalisation of the campus and the increasing emphasis on distance learning programmes along with increasing commercialisation, all of which could be seen to militate against the traditional sense of a university community and therefore of the effectiveness of trying to instil shared values and shared understanding.

\section{Operational issues}

There was general agreement among the participants that a code of academic conduct was a good idea in principle ( $88 \%$ of participants agreed/strongly agreed), indeed, that is relatively close to the current system of academic regulations with the university's explicit plagiarism policy statement. Again, however, the respondents were markedly more cautious about its effectiveness in practice (Figure 1).

The concept of the honour pledge received moderate support in the ideal world situation, but this was significantly reduced when considered in a real world scenario (Figure 1). The main difference between an honour pledge and a 'normal' statement or declaration that students may be required to sign is the presence of a moral element, either explicit or implicit. As can be seen from Figure 5, 90\% (40\% strongly disagree + $50 \%$ disagree) of the student participants disagreed that having an honour pledge to sign would prevent plagiarism in reality (as opposed to $40 \%$ in an ideal situation). Similarly, there was a marked discrepancy between the ideal and real situations among staff. 


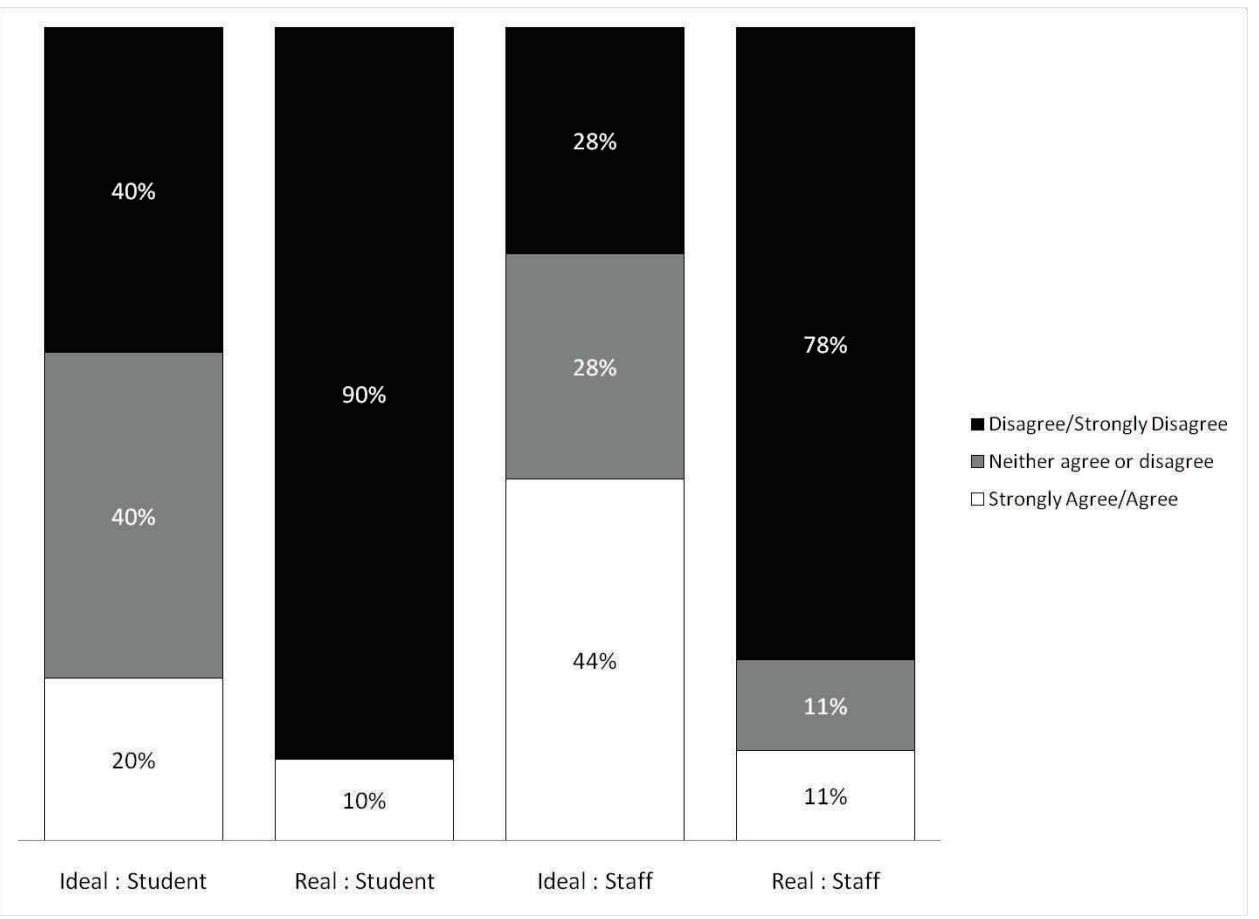

Figure 5: Responses of staff and students to ideal and real scenarios for the statement 'Having an honour pledge that students are required to sign' (students $n=10$; staff $n=18$ ).

Even if this idea appealed to some participants, particularly in the ideal world situation, the main argument against it seemed to be the difference in the perceptions of honour among individuals and different degrees of importance that people would place on the concept of honour:

Yeah, I don't... what is honour these days? I don't know, I'm not quite so sure... (StaffA6)

I think also it'd differ between student to student, whereas the university rules and regulations are the same for every student, but someone's perception of their honour is going to be vastly different to someone else's, so there's not consistency as for an imposed one. (StudB6)

This blurring of the meanings could be further exacerbated by perceived changes in students' value systems (Brimble \& Stevenson-Clarke, 2005). As a consequence, it was felt that there was a real problem of understanding: if students signed a clear statement confirming that the work was not plagiarised (rather than an honour pledge) there was less margin for misunderstanding. At the same time, the confidence attached to the last viewpoint must be tempered by the findings of several authors that the concept of plagiarism is poorly understood (McCabe, 2004; Carroll, 2004).

Some participants were skeptical about the whole idea of signing statements in that it may not mean a lot to students and that signing something does not imply understanding it or agreeing with it:

The principal thing is understanding what it means, isn't it? You can sign anything... (StaffC6)

Signing a piece of paper ... doesn't mean everything to people. At the beginning of uni, when you send a piece of work in, you sign you're not going to 
cheat, so you're not going to plagiarise, but yet people will still sign it even though they have plagiarised. (StudB8)

Additionally, some student participants noticed an intrinsic contradiction of the whole situation of 'we trust you but sign this please':

....and also in the ideal world you're saying that you trust the students, but you're still making them sign something, so that's going to send mixed messages. (StudB8)

Yeah, it's contradicting what you're saying in the first place (StudB9);

while others observed that (seemingly) less rigid regulations may be sending wrong messages to students:

I think it's the same for the honour pledge as well. If you put a lot of trust in students to kind of do it right, they may not view it as serious, they may be more likely to cheat or not be asked, it's just what I think. (StudC1)

It seems like a bit of a less rigid system, so there'll be probably a lot of discretions, they're not easy to stick to, whereas if you've got clear-cut rules and a clear declaration, you know what you're signing up for. (StudC4)

Furthermore, similar to the participants of Clarke and Aiello's (2007) study, views were expressed that pledges of this kind sound 'too American' due to their explicit sentimentality and may not be suitable in the UK context.

Staff and students rejected both the principle (60\% of staff and students against) and the reality ( $84 \%$ of participants against) of non-toleration (where members of the academic community are obliged to report any observed incidences of academic misconduct) as this was largely viewed as unworkable and non-enforceable.

Sounds quite Big Brotherish to me... (StaffA3)

The no-toleration clause, that's unfair. Nobody would want to tattletale their peers, but you've got to study with them for three years, you're going to be working with them, nobody would want to do it and put yourself in a corner like that. (StudB9)

The lack of support for unsupervised exams was expressed particularly strongly by the students, all of whom did not see this idea working effectively in reality.

\section{Student involvement}

Student involvement in the (re)writing of an academic code of conduct was cautiously supported by the participants in the ideal world scenario. In the real world situation, however, there was less support, which appeared to be due to the perceived practical difficulties of getting agreement across a wide section of the community and the strong belief by students that institutional rules should be sustainable prior to and beyond their tenure at university. The following comments typify the general student view:

At the end of the day, it's an academic institution, if they've got rules set, I think that's fair enough, whereas students who come in,... we would want different things in different ways... (StudA6) 
It is possible [to get a consensus], but you got to find the right group of people with the right motivation, right time, so it could, as far as I'm concerned, it could, but it could quite easily not. (StudA5)

On the issues of wider student involvement, such as peer-led teaching on academic integrity, the reception by staff was positive ( $88 \%$ of staff agreed/strongly agreed). The students were much less accepting of their potential involvement, with only $20 \%$ agreeing/strongly agreeing that they should be involved in peer-led education. There were concerns among students about possible misinterpretation of the regulations and the resultant consequences of being either on the giving or the receiving end of the peer education process, and staff participants also seemed to be aware of this problem, as well as of the wider issues of institutional responsibility and accountability.

A wholly student panel to hear cases and decide on penalties, both of which are far removed from current experience, were rejected outright by all the respondents (Figure 1). Partial student involvement on a hearing panel, however, was viewed more positively both in the ideal and the real situations $(75 \%$ and $64 \%$ of all participants respectively), and particularly by the staff where 12 of the 15 agreed with the proposal. The discussion in this context, though, raised a number of issues about the practicalities of the procedure. From the student perspective, one major concern was that they might know the person involved on either side of the panel:

I'm not sure about the student role though. I don't think it's anything to do with anyone else, I think there should just be... your teachers who were sorting it out. I don't think it's got anything to do with your fellow students... (StudC3)

...if the worst came to the worst, and you were brought up in front of a hearing, and then somebody on your course sat there who you know socially or you might be friends, or enemies and stuff, I think it'd make things a bit more complicated. (StudC1)

A further concern related to the experience of the panel:

They won't be able to judge another student because they don't have the experience of past students and what they've done, so l'd be probably more scared of a student body judging me than I would of an academic body... (StudB6)

The main support for the proposal of student involvement related to the view that there would be room for a sympathetic student viewpoint:

... sometimes I'd like to have a student voice in there, just to put a brake on some colleagues to say, 'Understand our perspective on this!' (StaffC6)

... a bit of an input from a student's point of view I think is necessary. (StudB9)

Overall, staff were markedly more enthusiastic about increased levels of student involvement in the practicalities of promoting academic integrity than students themselves.

\section{Conclusions}

This exploratory study appears to show that whilst the main principles of the American honour code system were broadly welcomed by the participants, their perceived practical implementation in the UK higher education context is more problematic. 
Although both staff and students saw educational benefits of increased student involvement in the promotion of academic integrity and good academic practice, there was a tension between staff who would like to increase the responsibilities of students and the reality of the students' seeming lack of confidence in their ability to carry out those responsibilities. It is clear that the moral element of the honour code was not welcomed, confirming the results of Clarke and Aiello (2007). However, the introduction of students as participants in plagiarism case panels and processes was tentatively supported and with sensitive planning could be introduced in the UK. This would sit well with the current agenda in the UK of increasing student involvement as co-producers in their own education and could begin a shift to begin breaking down the staff-student dichotomy.

There is a need for further research in this area in order to explore the potential benefits of the American-style honour code system more fully, and to consider the implications of introducing some of its elements within the UK context. This pilot study, based upon the views of a self-selected group could be expanded to a wider, more rigorously based series of focus groups across different universities. As a spinoff from this study, a working collaboration was established with the University's Students' Union who initiated a number of activities aimed at the promotion of principles of good scholarship and put forward a set of recommendations to the University including more publicity about the importance of good academic practice and Students' Union's involvement in educating students about plagiarism (Badge, Yakovchuk, Hancock, \& Porter, 2011). Recently, some interesting pedagogic models of promoting academic integrity within an holistic approach have been developed in Australia where, similarly to the UK, honour codes have not historically been part of the higher education culture (Freeman, Clarkeburn, \& Treleaven, 2007). The contextual factors are bound to shape the way in which the values and principles of academic integrity are embedded in the UK higher education setting. The recent agendas of internationalisation and widening participation, as well as the increasing numbers of part-time and distance learning students, are transforming the traditional perceptions of 'campus' and 'community', thus posing new challenges for the move towards a culture of academic integrity.

\section{References}

Badge, J., Yakovchuk, N., Hancock, A., \& Porter, A. (2011). Working together to reduce plagiarism and promote academic integrity: A collaborative initiative at Leicester. In S. Little (Ed.), Staff-student partnerships in higher education (pp. 48-61). London: Continuum.

Brimble, M., \& Stevenson-Clarke, P. (2005). Perceptions of the prevalence and seriousness of academic dishonesty in Australian universities. The Australian Educational Researcher, 32(3), 19-44. Retrieved http://www.aare.edu.au/aer/ online/50030b.pdf

Carroll, J. (2004). Six things I did not know four years ago about dealing with plagiarism. Paper presented at Educational integrity: Plagiarism and other perplexities, First Australasian Educational Integrity Conference. Adelaide, South Australia.

Center for Academic Integrity (2010). Retrieved November 25, 2011, from http:// www.academicintegrity.org/about_us/index.php

Center for Academic Integrity (1999). The fundamental values of academic integrity. Retrieved November 25, 2011, http://www.academicintegrity.org/ fundamental_values_project/pdf/FVProject.pdf

Clarke, J., \& Aiello, M. (2007). Codes contracts and consequences: The role of positive agreement in combating academic misconduct. Paper presented at Second International Plagiarism Conference. Newcastle upon Tyne, UK. Retrieved http://www.plagiarismadvice.org/images/stories/old_site/ media/2006papers/JohnClarke.pdf 
Duggan, F. (2006). Plagiarism: Prevention, practice and policy. Assessment \& Evaluation in Higher Education, 31(2), 151-154.

Flint, A., Clegg, S., \& MacDonald, R. (2006). Exploring staff perceptions of student plagiarism. Journal of Further and Higher Education, 30(2), 145-156.

Franklyn-Stokes, A., \& Newstead, S. E. (1995). Undergraduate cheating: Who does what and why? Studies in Higher Education, 20(2), 159-172.

Freeman, M., Clarkeburn, H., \& Treleaven, L. (2007). A collaborative approach to improving academic honesty. In A. Brew \& J. Sachs (Eds.), Transforming a university: The scholarship of teaching and learning in practice (153-161). Sydney: Sydney University Press.

Gabriel, T. (2010). Plagiarism lines blur for students in digital age. The New York Times, 1 August. Retrieved September 4, 2011, from http:// www.nytimes.com/2010/08/02/education/02cheat.html

Howard, R. M. (2007). Understanding "Internet plagiarism". Computers and Composition, 24(1), 3-15.

JISC (2011). Deterring, detecting and dealing with student plagiarism. Retrieved November 25, 2011, http://www.jisc.ac.uk/publications/briefingpapers/2005/ pub_plagiarism.aspx

Larkham, P. J., \& Manns, S. ( 2002). Plagiarism and its treatment in higher education. Journal of Further and Higher Education, 26(4), 339-349.

McCabe, D. L. (2000). New research on academic integrity: The success of "modified" honor codes. College Administration Publications, 15 May.

McCabe, D. L. (2004). Promoting academic integrity: A US/Canadian perspective. Paper presented at Educational integrity: Plagiarism and other perplexities, First Australasian Educational Integrity Conference. Adelaide, South Australia.

McCabe, D. L., \& Pavela, G. (2000). Some good news about academic integrity. Change, 32(5), 32-38. Retrieved September 4, 2011, from http:// abacus.bates.edu/cbb/events/docs/McCabe_Some.pdf

McCabe, D. L., \& Pavela, G. (2005). New honor codes for a new generation. Inside Higher Education, 11 March. Retrieved November 25, 2011, http:// www.insidehighered.com/views/2005/03/11/pavela1

McCabe, D. L., \& Treviño, L. K. (1993). Academic dishonesty: Honor codes and other contextual influences. Journal of Higher Education, 64(5), 522-538. Retrieved http://www.jstor.org/pss/2959991

McCabe, D. L., \& Treviño, L. K. (1997). Individual and contextual influences on academic dishonesty: A multicampus investigation. Research in Higher Education, 38(3), 379-396.

McCabe, D. L., \& Treviño, L. K. (2002). Honesty and honor codes. Academe Online 88/1. Retrieved November 25, 2011, http://www.aaup.org/AAUP/pubsres/ academe/2002/JF/Feat/mcca.htm

McCabe, D. L., Treviño, L. K., \& Butterfield, K. D. (1999). Academic integrity in honor code and non-honor code environments: A qualitative investigation. The Journal of Higher Education, 70(2), 211-234. Retrieved http://www.jstor.org/ pss/2649128

McCabe, D. L., Treviño, L. K., \& Butterfield, K. D. (2002). Honor codes and other contextual influences on academic integrity: A replication and extension to modified honor code settings. Research in Higher Education, 43(3), 357-378.

MacDonald, R., \& Carroll, J. (2006). Plagiarism - a complex issues requiring a holistic institutional approach. Assessment and Evaluation in Higher Education, 31(2), 233-245.

McGowan, U. (2005). Educational integrity: A strategic approach to anti-plagiarism. Paper presented at the APEIC 2005 Educational Integrity: Values in Teaching, Learning and Research. Newcastle, Australia. Retrieved http:// www.newcastle.edu.au/conference/apeic/papers_pdf/mcgowan_0548_edd.pdf 
Park, C. (2003). In other (people's) words: Plagiarism by university students literature and lessons. Assessment and Evaluation in Higher Education, 28(5), 471-488.

Park, C. (2004). Rebels without a clause: Towards an institutional framework for dealing with plagiarism by students. Journal of Further and Higher Education, 28(3), 291-306.

Selwyn, N. (2008). "Not necessarily a bad thing ...": A study of online plagiarism amongst undergraduate students. Assessment \& Evaluation in Higher Education, 33(5), 465-479.

Shepherd, J. (2007). An idea worth imitating. The Guardian, 20 March. Retrieved September 4, 2011, from http://www.guardian.co.uk/education/2007/mar/20/ highereducation.students

Trost, K. (2009). Psst, have you ever cheated? A study of academic dishonesty in Sweden. Assessment \& Evaluation in Higher Education, 34(4), 367-376.

Vandehey, M., Diekhoff, G., \& LaBeff, E. (2007). College cheating: A twenty-year follow-up and the addition of an honor code. Journal of College Student Development, 48(4), 468-480.

\section{About the authors}

\section{Dr Nadya Yakovchuk}

Nadya works as a Thinking Writing adviser at Queen Mary, University of London and as an associate lecturer at the Open University. She is currently a project officer on the Research-based Learning and Writing project at QMUL and is also actively involved in designing materials and running workshops on writing development for QMUL students, as well as teachers and students from local schools. Nadya's recent research focused on the incidence and causes of plagiarism in the academic writing of international students (PhD research, University of Warwick), and on promoting the culture of academic integrity and fostering student responsibility for their learning (Academic Integrity Project, University of Leicester).

Nadya has worked at a number of UK universities teaching linguistics, EAP and study skills, and she has also presented and published in the areas of plagiarism prevention and writing development. Her current professional interests include the development of discipline-specific writing, academic genre analysis, source use in student writing, plagiarism prevention and student learning experiences in HE.

\section{Dr Joanne Badge}

As web resources development officer Dr Badge encouraged the uptake of electronic systems and software to deliver teaching in the School of Biological Sciences at the University of Leicester. She was responsible for piloting and evaluating the first use of plagiarism scanning software at the School and subsequently at the institutional level. As a member of the academic advisory group for TurnitinUK, she provided advice and guidance on the service for UK Higher Educational Institutions. Dr Badge is now pursuing a career as a school teacher.

\section{Dr Jon Scott}

Jon read biological sciences at Durham University and stayed there to study for his $\mathrm{PhD}$, on sensory feedback from muscle. He then moved to Paris as a research fellow at the College de France before returning to Durham as a lecturer in zoology.

From Durham, Jon moved to a lectureship in physiology at Leicester, working on the control of movement. Jon became increasingly involved in developments in learning and teaching and in 1999 became Director of Biological Studies before being appointed Academic Director of the College of Medicine, Biological Sciences and Psychology. 
With the increasing focus on teaching and learning, Jon has led a number of projects in the areas of assessment and feedback; plagiarism, with emphasis on policy development; retention and the student experience; and reward and recognition of teaching and learning. In 2011 he was named UK Bioscience Teacher of the Year and elected to a Fellowship of the Society of Biology.

An earlier version of this paper was originally published in the refereed proceedings of the $5^{\text {th }}$ Asia Pacific Conference on Educational Integrity: Culture and values. The University of Western Australia, 26-28 September: http://www.apcei.catl.uwa.edu.au/ procs 